\title{
PENGEMBANGAN POTENSI DESA KEDISAN TEGALLALANG MELALUI PENERAPAN ALAT TEKNOLOGI TEPAT GUNA
}

\author{
I.M.D.B. Penindra ${ }^{1}$, D.M.P. Wedagama ${ }^{2}$
}

\begin{abstract}
ABSTRAK
Desa Kedisan merupakan salah satu desa yang terletak di Kecamatan Tegallalang, Kabupaten Gianyar. Lokasi Desa Kedisan berdekatan dengan Sungai Petanu di sebelah timur serta panorama Ceking di sebelah barat. KKN PPM di Desa Kedisan telah terlaksana dengan baik berkat kerjasama dari masyarakat, mahasiswa dan dukungan penuh dari pejabat Desa Kedisan. Adapun program yang telah dijalankan selama kegiatan adalah Penyuluhan intensif tentang peningkatan kualitas dan kuantitas hasil produksi kerajinan serta pembuatan mesin pengering dan pembuatan Art Shop di "WARTA SHOP", penyuluhan mengenai penyakit tanaman padi dan pemanfaatan kotoran hewan ternak untuk pupuk organik dan pembuatan biogas pada kelompok tani ternak, penyuluhan tentang pemanfaatan kotoran babi melalui pembuatan biogas di tempek Manik Sawang, penyuluhan intensif DBD serta pelatihan Self Jumantik di wilayah desa, pemberdayaan lansia melalui latihan senam lansia serta pemeriksaan kesehatan tulang gratis bekerjasama antara mahasiswa, pemerintah kabupaten Gianyar dan PERWATUSI, penyuluhan cuci tangan dan tanaman obat keluarga obat keluarga (TOGA), pemberdayaan karang taruna melalui pelatihan tari bali bagi anak-anak dan karang taruna, pembersihan dan pemberian buku untuk perpustakaan di SD, mengadakan pelatihan bahasa asing, pelajaran dasar, penyuluhan AIDS, narkotika dan psikotropika, penanaman pohon cempaka, albesia, dan Intaran di sekitar lingkungan Desa Kedisan, pembuatan program kependudukan untuk Desa Kedisan, pengadaan tong sampah dan gotong royong rutin serta pembuatan papan nama Desa, objek wisata serta rambu-rambu jalan yang penting di wilayah Desa Kedisan, Kabupaten Gianyar.
\end{abstract}

Kata Kunci : Desa Kedisan, biogas, AIDS dan psikotropika, biocas, RB

\begin{abstract}
Kedisan village is located in Tegalalang District, Gianyar Regency. It is near to Petanuriver with Ceking view on the west side. KKN PPM at Kedisan village has been done successfully collaborated with society, students and fully supported by the officer of Kedisan village. The program that have been held are intensive counseling about increasing quality and quantity of handicrafts product and producing drier machine and also Art shop at "Warta Shop", counseling about disease of rice plant and the using of pig manure for organic fertilizer and biogas production at ManikSawang neighborhood, Intensive counseling of DBD and self Jumantik training in village area, empowering elderly through gymnastic training and free examination bone health which is a collaboration between students and Gianyar district government and PERWATUSI, hand washing and family medication plant, youth empowerment through Balinese dance training for kids and youth, cleaning and book giving for elementary library, Foreign language training, basic subject, AIDS, drugs and psychotropic counseling, magnolia champaca, albesia and intaran planting around Kedisan village, demography program for Kedisan village, procurement of garbage can, environment cleaning and making the village signage board, tourist destination and traffic sign in Kedisan village area.
\end{abstract}

Keywords : Kedisan Village, biogas, AIDS and psychotropic, biocas, RB

\footnotetext{
${ }^{1}$ Jurusan Teknik Mesin, Fakultas Teknik, Universitas Udayana. Kampus Unud Bukit Jimbaran -Bali, Email : budiana_penindra@yahoo.com

${ }^{2}$ Jurusan Teknik Sipil, Fakultas Teknik, Universitas Udayana. Kampus Unud Bukit Jimbaran-Bali, Email : priyantha_wedagama@gmail.com
} 


\section{PENDAHULUAN}

Desa Kedisan termasuk dalam dataran rendah dengan ketinggian 418 sampai dengan 563 meter diatas permukaan laut dengan iklim tropis. Desa Kedisan memiliki rata-rata curah hujan $187 \mathrm{ml}$ setiap bulan sehingga cukup baik untuk daerah pertanian.Oleh karena itu, masyarakat Desa Kedisan banyak yang bertumpu pada sektor pertanian, dimana di Desa Kedisan terdapat sebuah kelompok tani (Gapoktan) serta 8 (delapan) wilayah subak yang meliputi Subak Tangkup, Subak Kebon, Subak Pakudui, Subak Bayad, Subak Kedisan Kaja, Subak Kedisan Kelod, Subak Cebok dan Subak Padang. Desa Kedisan memiliki lahan pertanian yang berupa lahan basah dan tegalan. Selain sektor pertanian, masyarakat Desa Kedisan juga banyak yang bergerak pada industri kerajinan, dimana sebagian besar produknya berupa patung-patung, ukiran, anyaman sok kasi (sarana sembahyang umat Hindu), patung dan ukiran. Kerajinan yang sedang naik daun saat ini Banjar Kedisan Kaja yakni tempat pembuatan quotes in frame. Permasalah yang dihadapi Bapak I Ketut Warta beserta pengerajin lainnya adalah cuaca. Saat cuaca memasuki musim hujan, beliau seringkali kebingungan karena kayu frame nya tidak dapat kering saat dijemur padahal pesanan terus menumpuk. Pada KKN kali ini kami akan membantu Pengerajin I Ketut Warta melalui pembuatan alat pengering kayu frame serta bantuan pembuatan art shop untuk meningkatkan penjualan. Hal penting lainnya menurut kepala desa, masyarakat, serta karang taruna adalah peningkatan kesadaran masyarakat akan pentingnya kesehatan dan pendidikan. Agar taraf hidup dapat meningkat tentunya kesehatan serta pendidikan masyarakatnya haruslah baik. Pada tahun 2015 Gianyar merupakan daerah yang memiliki kasus Demam Berdarah tertinggi di Bali yaitu 2032 orang pasien dengan 6 korban meninggal (sumber : P2PL Dinas Kesehatan Provinsi Bali : 3 Januari 2016). Mengingat siklus wabah DBD adalah Maret-Agustus maka salah satu program dalam KKN PPM di bidang kesehatan kali ini yaitu program penyuluhan intensif DBD serta pelatihan self jumantik (juru pemantau jentik) termasuk tentang sanitasi di seluruh wilayah Desa Kedisan, pelatihan senam lansia serta pemeriksaan kesehatan tulang gratis bekerjasama antara mahasiswa, pemerintah kabupaten Gianyar dan PERWATUSI yaitu yayasan Wanita yang fokus bergerak tentang kesehatan tulang, penyuluhan cuci tangan dan tanaman obat keluarga (TOGA), serta penyadaran akan pentingnya pendidikan. Untuk bidang pendidikan kami akan memfokuskan pada kelompok usia muda remaja sebagai generasi penerus di Desa Kedisan seperti pemberian les pelajaran dasar dan bahasa asing serta program pemberian sumbangan buku yang bertujuan untuk menumbuhkan kecintaan terhadap buku agar dapat memperluas wawasan mereka. Agar program ini berjalan dengan efektif sangat diperlukan adanya pemberdayaan masyarakat melalui pendampingan Perguruan tinggi. Fungsi dari pendamping adalah sebagai fasilitator dalam pelaksanaan pelatihan - pelatihan serta memotivasi masyarakat agar dapat meningkatkan taraf hidup mereka. Pendampingan dilakukan dengan melibatkan mahasiswa dibawah koordinasi dosen pembimbing lapangan. Dalam konteks ini, kegiatan pendampingan akan dilakukan melalui program Kuliah Kerja Nyata Pemberdayaan Masyarakat (KKN PPM) di Desa Kedisan.

Adapun tujuan kegiatan KKN PPM di Desa Kedisan adalah memberdayakan masyarakat maupun kelompok masyarakat di desa Kedisan, Kecamatan Tegallalang, Kabupaten Gianyar. Untuk mencapai tujuan tersebut dapat dijabarkan dalam bentuk yang spesifik sebagai berikut:

1. Pemberdayaan para pengerajin Quote in Frame yang salah satunya adalah WARTA SHOP melalui pembuatan mesin pengering kayu frame serta pembuatan art shop agar mampu meningkatkan produksi terutama saat musim hujan.

2. Pemberdayaan kelompok Tani Ternak di Desa Kedisan melalui peningkatan pengetahuan \& keterampilan mengenai cara pembuatan pupuk organik dari pemanfaatan kotoran ternak sapi serta pembuatan pakan ternak dengan teknik Biocas.

3. Penyuluhan tentang pemanfaatan kotoran babi melalui pembuatan biogas di tempek Manik Sawang.

4. Penyadaran masyarakat terhadap kesehatan diri serta kesehatan lingkungan

5. Meningkatkan pengetahuan dasar dan bahasa asing bagi anak-anak dan kelompok karang taruna sebagai generasi penerus.

34 | BULETIN UDAYANA MENGABDI 
6. Meningkatkan kepedulian dan empati mahasiswa kepada permasalahan masyarakat ekonomi lemah melalui pendampingan KK miskin.

\section{METODE PELAKSANAAN}

Metode Pelaksanaan Kuliah Kerja Nyata - Pemberdayaan Masyarakat (KKN-PPM) kali ini dilaksanakan dengan beberapa tahap yaitu persiapan, pelaksanaan, serta evaluasi. Persiapan yang dilakukan sebelum proposal dibuat adalah pertemuan awal yang dilakukan dosen pembimbing beserta beberapa perwakilan mahasiswa melakukan audensi kepada aparat desa serta melakukan pertemuan langsung dengan masyarakat dan juga perwakilan kelompok usaha. Adapun tujuan dari pertemuan ini adalah saling bertukar pengalaman dengan harapan teridentifikasilah permasalahanpermasalahan yang ada dimasyarakat. Setelah menyusun rencana kerja, maka dilakukanlah pembekalan kepada mahasiswa peserta KKN PPM dimana mahasiswa sebagai komponen motivator, fasilitator, dan komunikator di lapangan dan juga dilakukan General Test (GT) untuk menilai kesiapan dari mahasiswa yang akan turun ke Desa. Tahap berikutnya adalah pelaksanaan, pada tahap ini diimplementasikan rencana kegiatan yang telah di susun berdasarkan prioritas permasalahan yang ada di lapangan. Tahap pelaksanaan dilakukan pada minggu pertama bulan juni sampai minggu kedua bulan agustus 2017 . Tahap pelaksanaan meliputi pelaksanaan penyuluhan, pelaksanaan kegiatan pendukung dan evaluasi kegiatan dengan cara wawancara langsung kepada peserta dan perangkat desa yang ikut serta dalam kegiatan ini. Tahap pelaksanaan meliputi pelaksanaan penyuluhan, pelaksanaan kegiatan pendukung dan evaluasi kegiatan dengan cara wawancara langsung kepada peserta dan perangkat desa yang ikut serta dalam kegiatan ini.

Universitas Udayana melalui surat keputusan Rektor nomer 25/J14.KN.00.01/2003 tanggal 5 Desember 2003 telah menetapkan KKN sebagai mata kuliah pilihan. Seperti tertuang dalam UU RI nomor 20 tahun 2003, dinyatakan Perguruan tinggi berkewajiban menyelenggarakan pendidikan, penelitian dan pengabdian masyarakat. Unud dengan konsisten melaksanakan fungsi tersebut melalui lembaga yang menjalankan fungsi tersebut adalah LPPM. Dengan visinya yaitu menjadikan Universitas Udayana sebagai universitas yang unggul, mandiri, dan berbudaya yang berbasis pada penelitian maka dari itu pelaksanaan KKN PPM di Univeristas Udayana sangatlah layak. Dengan ditunjang adanya grup riset yang berjumlah lebih dari 130 grup riset yang di ketuai para guru besar, kami yakin secara institusional dengan bersinerginya grup riset, Unud mampu menyelesaikan masalah- masalah di masyarakat khususnya di Desa Kedisan, Kecamatan Tegallalang, Kabupaten Gianyar, Provinsi Bali.

\section{HASIL DAN PEMBAHASAN}

Penyuluhan intensif tentang peningkatan kualitas dan kuantitas hasil produksi kerajinan serta pembuatan mesin pengering dan pembuatan Art Shop di "WARTA SHOP” di Desa Kedisan, Kabupaten Gianyar

Kegiatan pada program ini terdiri dari pembuatan mesin pengering kayu untuk Bapak Warta dimana beliau merupakan salah satu pengrajin kayu kurang mampu di Banjar Bayad, Desa Kedisan sehingga permasalahan pengeringan terutama pada musim hujan dapat teratasi melalui penerapan mesin ini. Selain pembuatan mesin pengering, pada program KKN ini juga membuat Art Shop untuk meningkatkan penjualan karena selama ini hanya ada workshop.

Penyuluhan mengenai penyakit tanaman padi dan pemanfaatan kotoran hewan ternak untuk pupuk organik dan pembuatan biogas pada kelompok tani ternak Desa Kedisan, Kabupaten Gianyar

VOLUME 17 NOMOR 2, APRIL 2018 | 35 
Kegiatan dari program ini terdiri pemberian materi oleh 2 Guru besar dari Fakultas Pertanian Universitas Udayana mengenai penyakit tanaman padi, setelah itu dilanjutkan dengan pemberian materi oleh salah satu dosen dari Fakultas Peternakan Universitas Udayana mengenai pemanfaatan kotoran hewan untuk dijadikan pupuk organik dan terakhir dilakukan demonstrasi cara membuat pupuk organik dengan menggunakan BIOCAS dan RB.

Penyuluhan tentang pemanfaatan kotoran babi melalui pembuatan biogas di tempek Manik Sawang

Kegiatan utama program ini terdiri dari pembuatan Biogas di Tempek Manik Sawang, tepatnya dirumah Bapak Lasya. Bantuan Biogas diberikan kepada Bapak Lasya. Pembuatan Biogas ini dilakukan hingga kompor khusus Biogas menyala.

Penyuluhan intensif DBD serta pelatihan Self Jumantik di wilayah Desa Kedisan, Kabupaten Gianyar

Pelaksanaan kegiatan monodisipliner bidang kesehatan ini dilakukan selama satu hari pada tanggal 4 Agustus 2017 di wilayah Banjar Kebon, Desa Kedisan, Kecamatan Tegallalang, Kabupaten Gianyar. Pada kegiatan ini mahasiswa dibagi menjadi empat kelompok untuk melakukan kegiatan Pemberantasan Sarang Nyamuk (PSN) pada tiap rumah warga yang berada di lingkungan Banjar Kebon. Dalam kegiatan ini setiap kepala keluarga juga diberikan bubuk abate gratis untuk digunakan secara berkala.

Pemberdayaan lansia di wilayah Desa Kedisan melalui latihan senam lansia serta pemeriksaan kesehatan tulang gratis bekerjasama antara mahasiswa, pemerintah kabupaten Gianyar dan PERWATUSI yaitu yayasan Wanita yang fokus bergerak tentang kesehatan tulang

Kegiatan ini dilaksanakan pada tanggal 5 Agustus 2017 berlokasi di Banjar Kedisan Kelod, Desa Kedisan. Program senam osteoporosis, pemeriksaan tulang gratis, dan pengobatan gratis dilakukan selama kurang lebih lima jam. Pelaksanaan senam osteoporosis, pemeriksaan tulang gratis, dan pengobatan gratis ini ditujukan kepada masyarakat di Desa Kedisan, khususnya masyarakat golongan lansia. Hal ini dikarenakan masih kurangnya perhatian terhadap kesehatan di lingkungan sekitar Desa Kedisan. Pihak-pihak yang terkait dan turut mendukung jalannya program ini adalah mahasiswa, Kepala Desa Kedisan, Siswa-siswi SD 1 Kedisan, Siswa-siswi SMP 3 Tegallalang, Perwatusi, Puskesmas Tegallalang I, dan Dinas Kesehatan Gianyar. Dengan dilakukannya senam osteoporosis, pemeriksaan tulang gratis, dan pengobatan gratis ini ditujukan kepada masyarakat di Desa Kedisan, diharapkan dapat meningkatkan pemahaman masyarakat tentang pentingya menjaga kesehatan di Desa Kedisan.

Penyuluhan cuci tangan dan tanaman obat keluarga obat keluarga (TOGA)

Kegiatan PHBS di sekolah tersebut bertujuan untuk meningkatkan kesadaran, pemahaman masyarakat khususnya untuk anak usia dini untuk mampu melakukan tindakan pencegahan dalam penularan penyakit melalui kegiatan cara mencuci tangan yang baik dan benar serta cara menyikat gigi yang baik dan benar sebelum melakukan kegiatan maupun setelah melakukan kegiatan agar terhindar dari masalah kesehatan seperti diare, cacingan, sakit gigi, gigi berlubang, sakit kulit, typus, sakit perut, ISPA dan lain sebagainya. 
Pelatihan tari bali bagi anak-anak dan karang taruna.

Kegiatan utama dari program ini dimulai dari pemilihan tarian yang akan dilatih yang dilanjutkan dengan mencari musik yang sesuai dengan tarian yang akan dilatih pada anak-anak. Lalu setiap minggunya sesuai dengan kesepakatan akan dilaksanakan pelatihan menari yang bertempat di Posko KKN Unud Br.Kedisan Kaja.

Pembersihan dan pemberian buku untuk perpustakaan di SD

Waktu pelaksanaan kegiatan ini dilakukan dalam jangka waktu 1 hari dimana kegiatan ini dilakukan pada tanggal 22 Agustus 2017 di SDN 3 Kedisan Kelod. Pada tahap pelaksanaan ini mahasiswa KKN membantu membersihkan ruangan yang selama ini digunakan sebagai perpustakaan. Kegiatan ini di sertai dengan penyerahan buku bacaan oleh mahasiswa kepada perwakilan pihak SDN 3. Dimana kegiatan bersih-bersih perpustakaan dan disertai dengan penyerahan buku bacaan ini berlangsung pada jam sekolah yaitu pukul 10.00 sampai 12.00 WITA.

Penyuluhan AIDS, Narkotika dan Psikotropika di karang taruna banjar seluruh desa Kedisan, Kabupaten Gianyar

Kegiatan Penyuluhan HIV/AIDS, Narkotika dan Psikotropika dilakukan selama satu hari yaitu pada Hari Minggu tanggal 6 Agustus 2017. Bertempat di Balai Banjar Kedisan Kelod. Kelompok sasaran dalam kegiatan ini yaitu Seka Teruna-Teruni se-Desa Kedisan. Pihak-pihak yang terkait dan turut mendukung jalannya program ini adalah Badan Narkotika Nasional, Kepala Desa dan Seka Teruna Teruni se- Desa Kedisan dan mahasiswa KKN PPM XV Desa Kedisan Universitas Udayana. Dengan adanya Kegiatan Penyuluhan HIV/AIDS, Narkotika dan Psikotropika, yang dimana kita menyadari bahwa saat ini pergaulan semakin bebas sehingga memicu terjadinya perbuatan-perbuatan yang tidak baik, diantaranya yaitu seks bebas dan mengkonsumsi obat-obatan terlarang.

Penanaman pohon cempaka, albesia, dan Intaran di sekitar lingkungan Desa Kedisan

Kegiatan program ini adalah melakukan penanaman pohon di Pura Ulun Suwi, Banjar Bayad, Desa Kedisan. Bibit pohon yang ditanam adalah pohon cempaka, intaran, dan albesya. Penanaman dilakukan oleh mahasiswa KKN bersama dengan STT Banjar Bayad pada sore hari yang dihadiri oleh Kelian Banjar

Pembuatan program kependudukan untuk Desa Kedisan

Kegiatan utama dari pembuatan Program Sensus Kependudukan ini adalah untuk mempermudah proses sistem input data Sensus Kependudukan dan pengurusan surat-surat/dokumen penting sehingga proses pengerjaannya lebih efisien dan cepat. Hal ini guna mendukung kinerja PERBEKEL Desa Kedisan dan mengimplementasikan Ilmu yang diperoleh mahasiswa di kampus

\section{Pengadaan tong sampah dan gotong royong rutin di Banjar Bayad, Desa Kedisan, Gianyar}

Pada kegiatan ini dilakukan gotong royong pada lokasi yang sudah ditentukan yakni pada Br. Kedisan Kaja terletak di Pura Taman, pada Br. Kedisan Kelod terletak di Lapangan Umum, dan pada Br. Bayad dilakukan saat acara jalan sehat diadakan. Gotong royong dilakukan dengan membersihkan sampah yang ada baik dengan disapu ataupun dipungut dan merambah tanamantanaman yang kurang rapi. Untuk gotong royong di Br. Bayad saat jalan santai dilakukan dengan memunguti sampah sepanjang trek jalan santai dan titik berkumpul jalan sehat. 
Pembuatan papan nama Desa, objek wisata serta rambu-rambu jalan yang penting di wilayah Desa Kedisan, Kabupaten Gianyar

Kegiatan utama dari program ini dimulai dengan melakukan survei terhadap tempat pembuatan papan insformasi,lokasi pemasangan, serta mengkonfirmasi mengenai isi informasi kepada pihak pihak yang bersangkutan. Dimana isi dari informasi tersebut adalah kantor kelian banjar dinas kedisan kelod, Linmas, PKK, 10 program pokok PKK, Posyandu, Sekaa gong, KSP Gunung Artha, STT.

\section{KESIMPULAN DAN SARAN}

KKN PPM di Desa Kedisan telah terlaksana dengan baik berkat kerjasama dari masyarakat, mahasiswa dan dukungan penuh dari pejabat Desa Kedisan. Mengingat sangat dirasakan manfaat dari program KKN di Desa Kedisan oleh masyarakat dan pejabat Desa, maka hendaknya KKN PPM tidak dibuat dalam program Mono tahun tetapi sebaiknya dibuat dalam program Multi tahun sehingga pengabdi dapat mengimplementasikan program yang berkesinambungan sampai akhirnya dapat mewujudkan desa yang mandiri.

\section{UCAPAN TERIMAKASIH}

Terima kasih kami ucapakan kepada Dirjen Ristekdikti, LPPM Unud semua pihak yang baik secara langsung maupun tak langsung turut menyukseskan program KKN PPM ini.

\section{DAFTAR PUSTAKA}

DP2M DIRJEN DIKTI, 2013, Panduan Pelaksanaan Hibah Kuliah Kerja Nyata - Pembelajaran Pemberdayaan Masyarakat (KKN PPM).

Dewi, Meira, 2011, Pengaruh Usaha Kelompok Wanita Tani "Mekar Usaha" Terhadap Pendapatan Keluarga Di Banjar Dinas Saren Kauh, Desa Budakeling, Kecamatan Bebandem, Kabupaten Karangasem Tahun 2011.

Hikmat, Harry, 2001, "Strategi Pemberdayaan Masyarakat", Bandung, Humaniora Utama Press.

Sumodiningrat, Gunawan, 1997, "Pembangunan Daerah dan Pemberdayaan Masyarakat", Jakarta, Bina Rena Pariwara.

Hermawati, Istiana, 2012, Pemberdayaan Fakir Miskin Melalui Pemanfaatan Teknologi Rekayasa Pembesaran Udang Galah Di Desa Budakeling Kecamatan Bebandem Kabupaten Karangasem Provinsi Bali, Tim Pelaksana Insentif Peningkatan Kemampuan Peneliti dan Perekayasa. 